\title{
Nutrientes na serapilheira acumulada em um povoamento de Eucalyptus saligna Smith em São Grabriel, RS. ${ }^{1}$
}

\author{
Joel Carvalho dos Santos ${ }^{2}$; Mauro Valdir Schumacher ${ }^{3}$; Rudi Witschoreck ${ }^{4}$; Elias Frank de Araújo ${ }^{5}$; \\ Vicente Guilherme Lopes ${ }^{6}$
}

Resumo: O objetivo deste trabalho foi, quantificar o estoque de nutrientes na serapilheira acumulada em um povoamento de Eucalyptus saligna Smith aos 4 e 5 anos de idade no município de São Gabriel - RS. Todo o material coletado, ao final de cada estação do ano, foi enviado para o Laboratório para determinação dos macronutrientes. O total de serapilheira acumulada sobre o solo para os anos de 2011 e 2012 foi de 12,76 e $12,00 \mathrm{Mg} \mathrm{ha}^{-1}$, respectivamente. As quantidades de N, P, K, Ca, Mg e S estocadas na serapilheira foram de 94,$4 ; 4,8 ; 21,8 ; 138,8 ; 25,6$ e $8,8 \mathrm{~kg} \mathrm{ha}^{-1}$ respectivamente. A serapilheira acumulada é uma excelente fonte de matéria orgânica e reserva de nutrientes para as rotações futuras.

Palavras - chave: Ciclagem de nutrientes; Solos Florestais; Nutrição Florestal.

\section{Nutrients in the litter in an Eucalyptus saligna Smith stand in São Grabriel, RS.}

\begin{abstract}
The aim of this work was quantify the stock of nutrients in litter in a Eucalyptus saligna Smith stand at 4 and 5 years of age in the municipality of São Gabriel - RS. All material collected at the end of each season, was sent to the laboratory for determination of macronutrients. Total litter for the years 2011 and 2012 was 12.76 and $12.00 \mathrm{Mg} \mathrm{ha}^{-1}$, respectively. The amounts of N, P, K, Ca, Mg and S stored in the litter were 94.4; 4.8; 21.8; 138.8; 25.6 and $8.8 \mathrm{~kg} \mathrm{ha}^{-1}$ respectively. The litter is an excellent source of organic matter and nutrient reserves for future rotations.
\end{abstract}

Keywords: Nutrient cycling; Forest Soils; Forest Nutrition.

\footnotetext{
${ }^{1}$ Recebido em 27.06.2014 e aceito para publicação como artigo científico em: 29.09.2014.

${ }^{2}$ Acadêmico, do Curso de Engenharia Florestal, Centro de Ciências Rurais, Universidade Federal de Santa Maria, Av. Roraima, 1000, CEP 97105-900, Santa Maria (RS). Bolsista PIBIC/CNPq. E-mail <joelufsm@gmail.com>.

${ }^{3}$ Engenheiro Florestal, Dr. rer. nat. techn., Professor do Departamento de Ciências Florestais, Centro de Ciências Rurais, Universidade Federal de Santa Maria. E-mail: <mvschumacher@gmail.com>.

${ }^{4}$ Engenheiro Florestal, Dr. Pesquisador do Laboratório de Ecologia Florestal, Universidade Federal de Santa Maria. Av. Roraíma 1000, CEP: 97105-900. Santa Maria, RS. E-mail: <rwitschoreck@yahoo.com.br〉.

${ }^{5}$ Engenheiro Florestal, M. Sc Solos e Manejo da Celulose Rio-Grandense - CMPC.

${ }^{6}$ Engenheiro Florestal, Dr. Pesquisador do Laboratório de Ecologia Florestal, Universidade Federal de Santa Maria, Av. Roraima, 1000, CEP: 97105-900, Santa Maria (RS). E-mail: <viguilopes@yahoo.com.br>.
} 


\section{Introdução}

A manutenção da capacidade produtiva dos povoamentos de eucalipto está relacionada ao processo da ciclagem dos nutrientes, onde a serapilheira acumulada sobre o solo representa importante fonte de nutrientes. Informações a cerca desta dinâmica fornecem subsídios ao planejamento de ações voltadas às práticas silviculturais, principalmente manejo de adubação.

A ciclagem de nutrientes em ecossistemas florestais, segundo Souza e Davide (2001), tem sido amplamente estudada com o intuito de se obter maior conhecimento da dinâmica dos nutrientes nestes ambientes, não só para o entendimento do funcionamento dos ecossistemas, mas também para buscar informações a respeito de práticas de manejo florestal para a manutenção da produtividade do sítio.

Segundo Brun et al. (2001) a serapilheira pode ser definida como todos os tipos de materiais de origem vegetal, como flores, frutos, folhas, galhos, cascas dentre outros, que são depositados no piso florestal.

De acordo com Schumacher (1992) este acúmulo é influenciado diretamente pelas condições edafo-climáticas encontradas no local, podendo-se destacar a precipitação, temperatura e tipo de solo.

As folhas normalmente constituem a maior proporção da serapilheira devolvida ao solo, sendo que este percentual aumenta com a idade, até certo ponto, quando então, diminui devido ao aumento na queda de galhos e casca (REIS; BARROS, 1990). Para os mesmos autores, a deposição de serapilheira em povoamentos de eucalipto apresenta variação estacional. São principalmente fatores climáticos como temperatura e umidade que influenciam a intensidade de deposição da serapilheira nas diferentes épocas do ano, havendo diferenças pronunciadas entre espécies.

O ciclo de nutrientes de um dado ecossistema consiste na movimentação de nutrientes entre seus compartimentos e na transferência dos compartimentos em estudo com outros ecossistemas. Assim, nos ecossistemas, os elementos são continuamente transferidos entre os compartimentos bióticos e os abióticos (VIERA et al., 2008). A ciclagem de nutrientes abrange as trocas de elementos minerais entre os seres vivos e o ambiente que os circunda, centrando-se nas relações entre a vegetação e o solo.

A ciclagem de nutrientes através da queda de serapilheira é o meio mais importante para a nutrição dos vegetais, principalmente em solos de baixa fertilidade (Balieiro et al. 2004).

O objetivo do presente trabalho foi avaliar os nutrientes na serapilheira acumulada em um povoamento de Eucalyptus saligna.

\section{Material e métodos}

Características da área experimental

O presente trabalho foi realizado na Fazenda Ponta das Canas, em área experimental pertencente à empresa Celulose Riograndense CMPC, em um povoamento clonal de Eucalyptus saligna Smith aos quatro e cinco anos de idade no município de São Gabriel - RS.

Segundo a classificação de Köppen, o clima da região é classificado como $\mathrm{Cfa}$, onde a temperatura média anual é de $18,6{ }^{\circ} \mathrm{C}$ e a precipitação média anual é de $1356 \mathrm{~mm}$ (MALUF, 2000). Os valores da precipitação em 2011 e 2012 para a área de estudo foram de 1002,04 e 1224,73 $\mathrm{mm}$ respectivamente (Figura $1)$.

O solo da área de estudo é classificado como Argissolo Vermelho-Amarelo Distrófico típico (STRECK et al. 2008). As principais características do solo podem ser observadas na Tabela 1.

Segundo a Sociedade Brasileira de Ciência do solo/Comissão de Química e Fertilidade do solo (SBCS-CQFS, 2004), o teor de matéria orgânica no solo é baixo $(\leq 2,5 \%)$; o $\mathrm{pH}$ é muito baixo $(\leq$ $5,0) ;$ o $\mathrm{P}$ só é considerado adequado para a profundidade de $0-20 \mathrm{~cm}\left(\leq 7,0 \mathrm{mg} \mathrm{dm}^{-3}\right)$, para as demais profundidades é considerado muito baixo. $\mathrm{O} \mathrm{K}$ é de médio a alto para as duas 
primeiras profundidades $\left(40-120 \mathrm{mg} \mathrm{dm}^{-3}\right) ; \mathrm{Ca}$ e $\mathrm{Mg}$ são baixos $\left(\leq 2,0 \mathrm{e} \leq 0,5 \mathrm{cmol}_{\mathrm{c}} \mathrm{dm}^{-3}\right.$, respectivamente); a saturação por $\mathrm{Al}$ é alta (>
$20 \%)$ e a saturação por bases é muito baixa (< $45 \%)$.

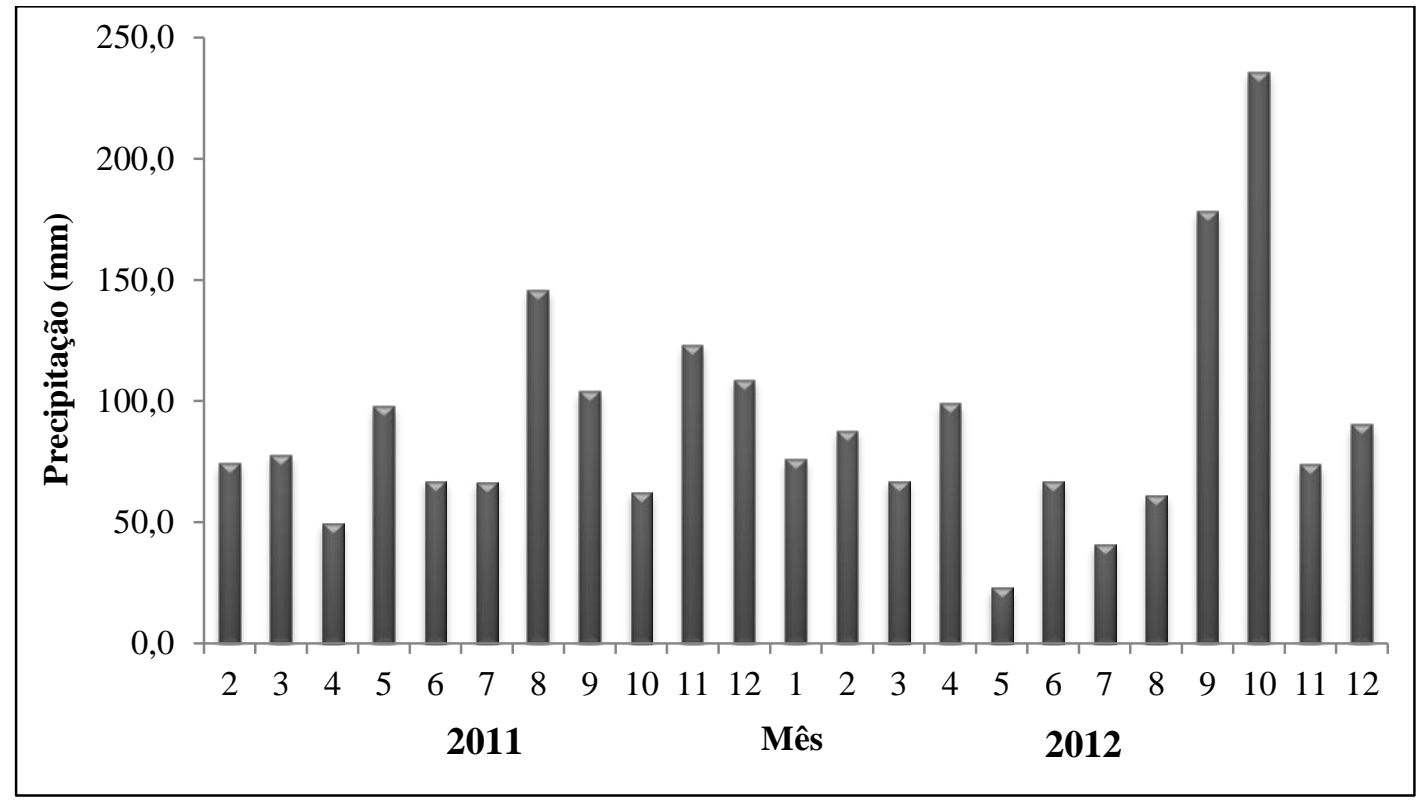

Figura 1: Alterações na precipitação pluviométrica mensal (mm) durante os anos de 2011 e 2012.

Figure 1: Changes in monthly rainfall $(\mathrm{mm})$ during the years 2011 and 2012.

Tabela 1: Principais características do solo do povoamento de Eucalyptus saligna.

Table 1: Main soil characteristics of the Eucalyptus saligna stand.

\begin{tabular}{|c|c|c|c|c|c|c|c|c|c|c|}
\hline \multirow{2}{*}{$\begin{array}{l}\text { Profundidade } \\
\qquad(\mathrm{cm})\end{array}$} & Argila & MO & \multirow{2}{*}{$\begin{array}{c}\mathrm{pH} \\
\left(\mathrm{H}_{2} \mathrm{O}\right)\end{array}$} & $\mathrm{Al}$ & $\mathrm{Ca}$ & $\mathrm{Mg}$ & $\mathrm{P}^{*}$ & $\mathrm{~K}^{*}$ & V & $\mathrm{m}$ \\
\hline & \multicolumn{2}{|c|}{$\%$} & & \multicolumn{3}{|c|}{$\mathrm{cmol}_{\mathrm{c}} \mathrm{dm}^{-3}$} & \multicolumn{2}{|c|}{$\mathrm{mg} \mathrm{dm}-3$} & \multicolumn{2}{|c|}{$\%$} \\
\hline $0-20$ & 12,6 & 1,7 & 4,1 & 2,0 & 0,6 & 0,4 & 13,2 & 51,6 & 11,7 & 64,3 \\
\hline $20-40$ & 25,3 & 1,7 & 4,3 & 3,0 & 0,8 & 0,2 & 3,3 & 42,7 & 10,1 & 70,1 \\
\hline $40-60$ & 25,3 & 1,3 & 4,4 & 2,6 & 1,1 & 0,2 & 2,6 & 30,8 & 17,6 & 59,4 \\
\hline
\end{tabular}

V: Saturação por bases; m: Saturação por Alumínio; MO: Matéria orgânica. Extrator Melich I.

Para implantação do povoamento foi realizado preparo do solo subsolagem a $50 \mathrm{~cm}$ com trator de pneu, e adubação com $2000 \mathrm{~kg} \mathrm{ha}^{-}$ ${ }^{1}$ de calcário a lanço $+500 \mathrm{~kg} \mathrm{ha}^{-1}$ de fosfato reativo no sulco de preparo $+100 \mathrm{~g} / \mathrm{pl}$ de NPK 06:30:06 no plantio em coveta lateral $+200 \mathrm{~g} / \mathrm{pl}$ de NPK 12:00:20 com 0,5\% Boro aos 120 dias + $200 \mathrm{~kg} \mathrm{ha}^{-1}$ de NPK 12:00:20 aos 12 meses.

Após a implantação do povoamento de Eucalyptus saligna com espaçamento de $3,5 \mathrm{~m} \mathrm{x}$ $2,75 \mathrm{~m}$, realizou-se alguns tratos silviculturais na área como uma capina química em área total com glifosato (scout - $2 \mathrm{~kg} \mathrm{ha}^{-1}$ ) + aplicação de pré-emergente (GOAL BR - $41 \mathrm{ha}^{-1}$ ) na linha +2 tratos culturais com glifosato aos 90 dias e aos 9 meses.

\section{Metodologia de estudo}

Para a estimativa da serapilheira acumulada, foram coletadas aleatoriamente 16 amostras em cada uma das 4 parcelas $(23 \mathrm{~m}$ x $26 \mathrm{~m})$, totalizando 64 amostras. Para isso, utilizou-se uma moldura com dimensões de $25 \mathrm{~cm} \mathrm{x} 25 \mathrm{~cm}$. Essas coletas foram realizadas ao final de cada estação do ano, no período de 2011 e 2012.

$\mathrm{O}$ material coletado nas parcelas foi 
devidamente identificado e posteriormente levado ao Laboratório e posto para secar em estufa de circulação e renovação de ar a $70^{\circ} \mathrm{C}$ por um período de 72 horas. Após a secagem foi obtido o peso seco das amostras. A determinação da quantidade de serapilheira por hectare foi obtida pela multiplicação da massa da serapilheira coletada no interior da moldura pela área do hectare.

Para a análise química, foram tomadas subamostras, da seguinte maneira: as quatro amostras por parcela foram misturadas retirando uma sub-amostra, totalizando quatro subamostras ao final de cada estação do ano para serem analisadas quimicamente. Antes das análises químicas, as sub-amostras foram moídas em moinho do tipo Wiley com peneira de 30 mesh. Sendo após determinadas as concentrações dos macronutrientes segundo metodologia descrita em Tedesco et al. (1995) e Miyazawa et al. (1999).

A partir do produto da massa da serapilheira, e a concentração de nutrientes nela contida, foi estimado a quantidade total de nutrientes por hectare.

As diferentes variáveis foram analisadas no delineamento inteiramente casualizado com parcela subdividida no espaço, tendo quatro níveis para o fator A (estações do ano) nas parcelas principais, dois níveis para o fator $\mathrm{D}$ (anos) nas subparcelas e quatro repetições. $\mathrm{Na}$ comparação de médias foi aplicado o teste de Tukey em nível de 5\% de probabilidade de erro. Em todas as análises foi utilizado o programa estatístico SAS.

\section{Resultados e Discussão}

Devido as maiores concentrações de $\mathrm{Ca}$ e $\mathrm{N}$ na serapilheira acumulada, esses nutrientes apresentaram as maiores quantidades nos diferentes materiais depositados sobre o solo (Tabela 2), independente da estação e ano, não diferindo estatisticamente.

As concentrações de N, P e Ca não diferiram significativamente $(p>0,05)$ entre as estações do ano estudadas para o ano de 2011. Para 2012 o $\mathrm{P}, \mathrm{Ca}, \mathrm{Mg}$ e $\mathrm{S}$ não diferiram significativamente entre as estações do ano.

Durante a estação do inverno a serapilheira apresentou maior concentração de $\mathrm{N}\left(8,23 \mathrm{~g} \mathrm{~kg}^{-}\right.$ $\left.{ }^{1}\right)$ não diferindo das demais estações em 2011. Já em 2012 o maior valor de $\mathrm{N}$ foi encontrado na primavera $\quad\left(9,69 \quad \mathrm{~g} \quad \mathrm{~kg}^{-1}\right), \quad$ diferindo significativamente das demais estações. Vital et al, (2004) estudando a produção de serapilheira de uma floresta estacional semidecidual, encontrou para a serapilheira acumulada uma média anual de 6,28 $\mathrm{Mg} \mathrm{ha}^{-1}$.

Viera et al, (2008) estudando o conteúdo de nutrientes na serapilheira acumulada em Eucalyptus grandis, encontrou valores médios para as concentrações de $\mathrm{K}$ e $\mathrm{Ca}$ bastante superiores aos encontrados no presente estudo, 10,46 e $19,73 \mathrm{~g} \mathrm{~kg}^{-1}$, respectivamente.

Dentre os elementos analisados, o $\mathrm{Ca}$ foi o que apresentou maior valor de concentração. Segundo Borém e Ramos (2002), o enriquecimento em cálcio na serapilheira pode ser decorrente de uma liberação mais lenta deste elemento pelo material recém caído da retranslocação de outros elementos antes da abscisão e/ou consequência da retenção de $\mathrm{Ca}$ contido na precipitação interna (chuva que atravessa o dossel) pela serapilheira acumulada.

Em relação ao $\mathrm{K}$, o mesmo diferiu significativamente entre as estações de ambos os anos, com maiores concentrações nas estações com maiores precipitações. O K é um elemento altamente solúvel e, por isso, facilmente lixiviável tanto de órgãos vegetativos vivos quanto mortos (MENGEL e KIRKBY, 1987; JONES JUNIOR, 1998).

Esse comportamento é corroborado pelos resultados observados por Britez (1994) e Souza (2006) em ambiente de Floresta Ombrófila Densa das terras baixas no litoral do estado do Paraná. Esses autores observaram que, após a interação da água da chuva com a vegetação, o $\mathrm{K}$ apresentou concentrações bem maiores na água que atravessou o dossel da floresta. No caso da serapilheira, esse mesmo comportamento é observado, sendo as quantidades de $\mathrm{K}$ encontradas no lixiviado da serapilheira acumulada provenientes de deposição seca e do próprio tecido vegetal. 
Tabela 2: Concentração média dos macronutrientes na serapilheira acumulada nas diferentes estações do ano.

Table 2: Mean concentration of macronutrients in litter in different seasons.

\begin{tabular}{|c|c|c|c|c|c|c|c|}
\hline \multirow{2}{*}{ Ano } & \multirow{2}{*}{ Estação } & $\mathrm{N}$ & $\mathrm{P}$ & $\mathrm{K}$ & $\mathrm{Ca}$ & $\mathrm{Mg}$ & S \\
\hline & & \multicolumn{6}{|c|}{$\left(\mathrm{g} \mathrm{kg}^{-1}\right)$} \\
\hline \multirow{4}{*}{2011} & Verão & $6,94 a^{*}$ & $0,36 \mathrm{a}$ & $2,73 \mathrm{a}$ & $9,00 \mathrm{a}$ & $1,94 \mathrm{~b}$ & $0,60 \mathrm{ab}$ \\
\hline & Outono & 6,93 a & $0,39 \mathrm{a}$ & $2,40 \mathrm{a}$ & $12,68 \mathrm{a}$ & $2,00 \mathrm{~b}$ & $0,42 \mathrm{~b}$ \\
\hline & Inverno & $8,23 \mathrm{a}$ & $0,48 \mathrm{a}$ & $1,30 \mathrm{~b}$ & $13,08 \mathrm{a}$ & $1,86 \mathrm{~b}$ & $0,55 \mathrm{ab}$ \\
\hline & Primavera & $7,28 \mathrm{a}$ & $0,31 \mathrm{a}$ & $1,18 \mathrm{~b}$ & $9,20 \mathrm{a}$ & $2,46 \mathrm{a}$ & $0,78 \mathrm{a}$ \\
\hline \multirow{4}{*}{2012} & Verão & $6,98 \mathrm{~b}$ & $0,39 \mathrm{a}$ & $1,34 \mathrm{~b}$ & $11,13 \mathrm{a}$ & $1,96 \mathrm{a}$ & $0,86 \mathrm{a}$ \\
\hline & Outono & $6,88 \mathrm{~b}$ & $0,33 \mathrm{a}$ & $1,96 \mathrm{a}$ & $9,23 \mathrm{a}$ & $1,96 \mathrm{a}$ & $0,85 \mathrm{a}$ \\
\hline & Inverno & $7,77 \mathrm{ab}$ & $0,40 \mathrm{a}$ & $1,75 \mathrm{ab}$ & $12,40 \mathrm{a}$ & $2,25 \mathrm{a}$ & $0,80 \mathrm{a}$ \\
\hline & Primavera & 9,69 a & $0,48 \mathrm{a}$ & $1,55 \mathrm{ab}$ & $12,68 \mathrm{a}$ & $1,98 \mathrm{a}$ & $0,83 \mathrm{a}$ \\
\hline
\end{tabular}

* Médias seguidas de mesma letra na vertical, para cada ano, não diferem entre si pelo teste de Tukey a 5\% de probabilidade de erro.

As quantidades de serapilheira acumulada para os anos de 2011 e 2012 nas diferentes estações do ano foram de 12,7 e $12,0 \mathrm{Mg} \mathrm{ha}^{-1}$, respectivamente (Tabela 3 ).

A serapilheira acumulada em florestas tropicais varia em torno de 2,1 a 12,5 $\mathrm{Mg} \mathrm{ha}^{-1}$, sendo difíceis comparações precisas por depender de diversos fatores, como produção de serapilheira, qualidade do substrato, declividade do terreno e pelas diferentes metodologias empregadas (SPAIN, 1984).

$\mathrm{Na}$ estação da primavera para os dois anos foram observados os maiores valores de quantidade de serapilheira acumulada sobre o solo.

Em povoamentos de eucalipto, existe uma grande variação na serapilheira acumulada sobre o solo. Essa variação pode ser verificada no estudo de Witschoreck e Schumacher (2000) com Eucalyptus spp., onde encontraram 4,05; 5,$98 ; 11,80$ e $12,28 \mathrm{Mg} \mathrm{ha}^{-1}$, quando os povoamentos encontravam-se com 2, 4, 6 e 8 anos de idade, respectivamente. Essa variação pode ser explicada de acordo com a variação do clima, de sítios, idade, densidade de plantio, diferentes características genéticas de cada espécie e da estabilidade alcançada pelo povoamento (VIERA et al., 2010). Devido a esses fatores, há variação na quantidade de material depositado e no tempo necessário para a sua decomposição, refletindo na maior ou menor acumulação de serapilheira sobre o solo.

Schumacher et al. (2002), avaliando o acúmulo de serapilheira em povoamentos de Eucalyptus urophylla, Eucalyptus cloesiana e Eucalyptus grandis, com nove anos de idade encontraram $16,7,16,5$ e $12,6 \mathrm{Mg} \mathrm{ha}{ }^{-1}$, respectivamente.

De todos os nutrientes observados, o Nitrogênio $(\mathrm{N})$ foi o elemento que apresentou maior diferença entre a menor e a maior quantidade de nutrientes. Essa diferença no ano de 2012 chega a $57,48 \mathrm{Kg} \mathrm{ha}^{-1}$, sendo a menor quantidade observada no outono $\left(74,60 \mathrm{Kg} \mathrm{ha}^{-1}\right)$ e a maior observada na estação da primavera $\left(132,08 \mathrm{Kg} \mathrm{ha}^{-1}\right)$.

Em relação à quantidade de serapilheira acumulada sobre o solo, não houve diferença estatística entre os anos e estações estudadas, tendo variação não significativa na produção e acúmulo de serapilheira no período de um ano.

Dentre os macronutrientes, o elemento que mais variou de uma estação para outra foi o $\mathrm{K}$. Apenas na primavera não houve diferença estatística entre os anos de 2011 e 2012. 
Tabela 3: Nutrientes na serapilheira acumulada em Eucalyptus saligna nos anos de 2011 e 2012.

Table 3: Nutrients in the litter in Eucalyptus saligna in the years 2011 and 2012.

\begin{tabular}{|c|c|c|c|c|c|}
\hline \multirow{2}{*}{ Ano } & \multicolumn{4}{|c|}{ Estação do ano } & \multirow{2}{*}{ Média } \\
\hline & Verão & Outono & Inverno & Primavera & \\
\hline \multicolumn{6}{|c|}{ Serapilheira $\left(\mathrm{Mg} \mathrm{ha}^{-1}\right)$} \\
\hline 2011 & $11,62 \mathrm{~A}$ & $12,68 \mathrm{~A}$ & $12,10 \mathrm{~A}$ & $14,62 \mathrm{~A}$ & 12,76 \\
\hline 2012 & $10,90 \mathrm{~A}$ & $10,85 \mathrm{~A}$ & $12,55 \mathrm{~A}$ & $13,68 \mathrm{~A}$ & 12,00 \\
\hline Média & $11,26 \mathrm{~b}$ & $11,77 \mathrm{ab}$ & $12,33 \mathrm{ab}$ & $14,15 \mathrm{a}$ & 12,38 \\
\hline \multicolumn{6}{|c|}{$\mathrm{N}\left(\mathrm{kg} \mathrm{ha}^{-1}\right)$} \\
\hline 2011 & $80,82 \mathrm{~A}$ & $87,98 \mathrm{~A}$ & $98,80 \mathrm{~A}$ & $106,58 \mathrm{~B}$ & 93,55 \\
\hline 2012 & $76,18 \mathrm{~A}$ & $74,60 \mathrm{~A}$ & $97,85 \mathrm{~A}$ & $132,08 \mathrm{~A}$ & 95,18 \\
\hline Média & $78,50 \mathrm{~b}$ & $81,29 \mathrm{~b}$ & $98,33 \mathrm{~b}$ & $119,33 \mathrm{a}$ & 94,36 \\
\hline \multicolumn{6}{|c|}{$\mathrm{P}\left(\mathrm{kg} \mathrm{ha}^{-1}\right)$} \\
\hline 2011 & $4,12 \mathrm{~A}$ & $4,70 \mathrm{~A}$ & $5,75 \mathrm{~A}$ & $4,55 \mathrm{~B}$ & 4,78 \\
\hline 2012 & $4,15 \mathrm{~A}$ & $3,55 \mathrm{~A}$ & $4,88 \mathrm{~A}$ & $6,57 \mathrm{~A}$ & 4,79 \\
\hline Média & $4,14 \mathrm{a}$ & $4,13 \mathrm{a}$ & $5,32 \mathrm{a}$ & $5,56 \mathrm{a}$ & 4,78 \\
\hline \multicolumn{6}{|c|}{$\mathrm{K}\left(\mathrm{kg} \mathrm{ha}^{-1}\right)$} \\
\hline 2011 & $31,52 \mathrm{~A}$ & $30,70 \mathrm{~A}$ & $15,75 \mathrm{~B}$ & $17,35 \mathrm{~A}$ & 23,83 \\
\hline 2012 & $14,58 \mathrm{~B}$ & $21,25 \mathrm{~B}$ & $22,10 \mathrm{~A}$ & $21,25 \mathrm{~A}$ & 19,80 \\
\hline Média & $23,05 \mathrm{a}$ & $25,98 \mathrm{a}$ & $18,93 \mathrm{a}$ & $19,30 \mathrm{a}$ & 21,81 \\
\hline \multicolumn{6}{|c|}{$\mathrm{Ca}\left(\mathrm{kg} \mathrm{ha}^{-1}\right)$} \\
\hline 2011 & $105,37 \mathrm{~A}$ & $162,00 \mathrm{~A}$ & $157,70 \mathrm{~A}$ & $134,05 \mathrm{~A}$ & 139,78 \\
\hline 2012 & $121,20 \mathrm{~A}$ & $100,07 \mathrm{~B}$ & $157,22 \mathrm{~A}$ & $172,95 \mathrm{~A}$ & 137,86 \\
\hline Média & $113,29 \mathrm{a}$ & $131,04 \mathrm{a}$ & $157,46 \mathrm{a}$ & $153,50 \mathrm{a}$ & 138,82 \\
\hline \multicolumn{6}{|c|}{$\operatorname{Mg}\left(\mathrm{kg} \mathrm{ha}^{-1}\right)$} \\
\hline 2011 & $22,65 \mathrm{~A}$ & $25,45 \mathrm{~A}$ & $22,45 \mathrm{~B}$ & $35,92 \mathrm{~A}$ & 26,62 \\
\hline 2012 & $21,42 \mathrm{~A}$ & $21,25 \mathrm{~A}$ & $28,38 \mathrm{~A}$ & $27,20 \mathrm{~B}$ & 24,56 \\
\hline Média & $22,04 \mathrm{~b}$ & $23,35 \mathrm{~b}$ & $25,42 \mathrm{ab}$ & $31,56 \mathrm{a}$ & 25,59 \\
\hline \multicolumn{6}{|c|}{$\mathrm{S}\left(\mathrm{kg} \mathrm{ha}^{-1}\right)$} \\
\hline 2011 & $6,92 \mathrm{~A}$ & $5,28 \mathrm{~B}$ & $6,65 \mathrm{~B}$ & $11,42 \mathrm{~A}$ & 7,57 \\
\hline 2012 & $9,32 \mathrm{~A}$ & $9,17 \mathrm{~A}$ & $10,10 \mathrm{~A}$ & $11,28 \mathrm{~A}$ & 9,97 \\
\hline Média & $8,12 \mathrm{~b}$ & $7,23 \mathrm{~b}$ & $8,38 \mathrm{~b}$ & $11,35 \mathrm{a}$ & 8,77 \\
\hline
\end{tabular}

Médias seguidas por letra minúscula diferente na horizontal diferem pelo teste de Tukey a $5 \%$ de probabilidade de erro. Médias seguidas por letra maiúscula diferente na vertical diferem pelo teste de $\mathrm{F}$ no desdobramento da interação das médias do fator D (ano) dentro dos níveis do fator A (estações) em 5\% de probabilidade de erro.

Para o Fósforo (P), os valores também foram semelhantes durante os dois anos de estudo. A baixa quantidade desse elemento pode ser explicada pelo processo de retranslocação que é facilmente observado em folhas principalmente. No Eucalyptus, 70 a $80 \%$ do $\mathrm{P}$ pode ser retranslocado antes da queda das folhas (GONÇALVES; BENEDETTI, 2005).
O Cálcio (Ca) manteve-se com valores médios semelhantes durante as estações em 2011 e 2012, com exceção do outono, onde diferiu estatisticamente pelo teste de Tukey. Tal fato pode ser explicado pela imobilidade do $\mathrm{Ca}$ nos tecidos vegetais.

A quantidade dos nutrientes $\mathrm{Ca}+\mathrm{N}$ corresponde a mais de $79 \%$ do total dos 
macronutrientes na serapilheira acumulada sobre o solo.

Viera (2012) estudando a quantidade de nutrientes na serapilheira acumulada em um povoamento de Eucalyptus urophylla $\mathrm{x}$ Eucalyptus globulus, encontrou resultado semelhante com o presente estudo, sendo $\mathrm{Ca}+\mathrm{N}$ correspondente a mais de $82 \%$ do total de macronutrientes na serapilheira sobre o solo.

A magnitude total da quantidade de macronutrientes na serapilheira foi de $\mathrm{Ca}>\mathrm{N}>$ $\mathrm{Mg}>\mathrm{K}>\mathrm{S}>\mathrm{P}$. Esta sequência é similar a mencionada por Haag (1985) em diversos estudos, havendo apenas a inversão entre as quantidades de $\mathrm{N}$ e $\mathrm{Ca}$, ocasionada pelo maior conteúdo de Ca nos materiais lenhosos, os quais não foram considerados pelo autor supracitado.

\section{Conclusões}

A serapilheira acumulada sobre o solo no ano de 2011 e 2012 foi de 12,76 e 12,00 Mg ha-1, respectivamente.

O acúmulo de serapilheira sobre o solo foi maior na primavera para ambos os anos de estudo em relação às demais estações.

Devido à grande quantidade de material orgânico acumulado sobre o solo, a serapilheira pode ser considerada como uma fonte importante de nutrientes para as árvores de Eucalyptus saligna.

\section{Referências}

BALIEIRO, F. C. et al. Dinâmica da serapilheira e transferência de nitrogênio ao solo, em plantios de Pseudosamanea guachapele e Eucalyptus grandis. Pesquisa Agropecuária Brasileira, Brasília, v.39, p.597-601, 2004.

BORÉM, R. A. T.; RAMOS, D. P. Variação estacional e topográfica de nutrientes na serapilheira de um fragmento de Mata Atlântica. Cerne, Lavras, v.8, n.2, p.042-059, 2002.

BRITEZ, R. M. Ciclagem de nutrientes minerais em duas florestas da planície litorânea da Ilha do Mel, Paranaguá, PR. 1994. 240 f. Dissertações (Mestrado em Engenharia Florestal) - Setor de Ciências Agrárias, Universidade Federal do Paraná, Curitiba. 1994.

BRUN, E. J. et al. Relação entre a produção de serapilheira e variáveis meteorológicas em três fases sucessionais de uma Floresta Estacional Decidual no Rio Grande do Sul. Revista Brasileira de Agrometeorologia, v.9, n.2, p.277-285, 2001.

GONÇALVES, J. L. M., BENEDETTI, V. Nutrição e Fertilização Florestal. Piracicaba: Instituto de Pesquisas e Estudos Florestais IPEF, 2005. 427p.

HAAG, H. P. Ciclagem de nutrientes em florestas tropicais. Campinas: Fundação Cargill, 1985. 144p.

JONES JUNIOR, J. B. Plant nutrition. Florida: CRC Press LLC, 1998. 149 p.

MALUF, J. R. T. Nova classificação climática do Estado do Rio Grande do Sul. Revista Brasileira de Agrometeorologia, v.8, n.1, p. 141-150, 2000.

MENGEL, K.; KIRKBY, E. A. Principles of plant nutrition. Berna: International Postash Institute, 1987.

MIYAZAWA, M. et al. Análises químicas de tecido vegetal. In: SILVA, F.C. (Org.). Manual de análises químicas de solos, plantas e fertilizantes. Brasília: Embrapa Comunicação para Transferência de Tecnologia, 1999. p.171224.

REIS, M. G. F.; BARROS, N. F. de. Ciclagem de nutrientes em plantios de eucalipto. In: BARROS, N. F.; NOVAIS, R. F. (eds.). Relação solo-eucalipto. Viçosa: Ed. Folha de Viçosa, 1990. p.265-296. 
SCHUMACHER, M. V. Aspectos da ciclagem de nutrientes e do microclima em talhões de Eucalyptus camaldulensis Dehnh, Eucalyptus grandis Hill ex Maiden e Eucalyptus torelliana F. Meiell. 1992. 87 f. Dissertação (Mestrado em Engenharia Florestal) - Escola Superior de Agricultura "Luiz de Queiroz" - Universidade de São Paulo, Piracicaba. 1992.

SCHUMACHER, M. V.; BAUERMANN, G. C.; COPETTI, L.; BRUN, E. J.; KONIG, F. G. Fracionamento da serapilheira em três espécies de eucalipto no município de Santa Maria-RS: Eucalyptus urophylla, Eucalyptus cloesiana e Eucalyptus grandis. In: $2^{\circ}$ CICLO DE ATUALIZACAO FLORESTAL DO CONESUL, 2002. Santa Maria RS, 2002. p.173180.

SOCIEDADE BRASILEIRA DE CIÊNCIA DO SOLO - COMISSÃO DE QUÍMICA E FERTILIDADE DO SOLO (SBCS-CQFS). Manual de adubação e de calagem para os estados do Rio Grande do Sul e de Santa Catarina. Porto Alegre: SBCS. 2004. 400p.

SOUZA, J. A.; DAVIDE, A. C. Deposição de serapilheira em uma mata não minerada e em plantações de bracatinga (Mimosa scabrella) e de eucalipto (Eucalyptus saligna) em áreas de mineração de bauxita. Cerne, Lavras, v.7, n.1, p.101-113, 2001.

SOUZA, L. C. Dinâmica de nutrientes na precipitação, em solução de solo e lençol freático em três tipologias florestais sobre Espodossolo, no Litoral do Paraná. 2006. 89 f. Tese (Doutorado em Ciências Florestais) - Setor de Ciências Agrárias, Universidade Federal do Paraná, Curitiba. 2006.

SPAIN, A.V. Litterfall and the standing crop of litter in three tropical Australian rainforests. Journal of Ecology 72(3): p. 947-961, 1984.

STRECK, E. V. et al. Solos do Rio Grande do Sul. 2.ed. Porto Alegre: Emater/RS, 2008. 222p.
TEDESCO, M. J.; GIANELLO, C.; BISSANI, C. A.; BOHNEN, H.; VOLKWEISS, S. J. Análise de solo, plantas e outros materiais. Porto Alegre, Departamento de Solos: UFRGS, 1995. 118 p. (Boletim Técnico No 5).

VIERA, M.; BACKES, K. S.; KANIESKI, M. R.; CHASSOT, T.; SOUTO, L.; SCHUMACHER, M. V. Conteúdo de nutrientes na serapilheira acumulada em povoamentos de Eucalyptus grandis, $E$. urophylla e E. cloeziana, no município de Santa Maria - RS. In: $5^{\circ}$ Simpósio de PósGraduação em Ciências Florestais, 5., 2008, Brasília. Anais... Brasília: Depto. Engenharia Florestal, 2008. p. $342-351$.

VIERA, M. et al. Nutrientes na serapilheira em um fragmento de floresta estacional decidual, Itaara, RS. Ciência Florestal, Santa Maria, v. 20, n. 4, p. 611-619, 2010.

VIERA, M. Dinâmica nutricional em um povoamento de Eucalyptus urophylla $\mathrm{X}$ Eucalyptus globulus. 2012. 120 f. Tese (Doutorado em Engenharia Florestal) Universidade Federal de Santa Maria, Santa Maria. 2012.

VITAL, A. R. T. et al. Produção de serapilheira e ciclagem de nutrients de uma floresta estacional semidecidual em zona ripária. Revista Árvore, v.28, n.6, p.793-800, 2004.

WITSCHORECK, R.; SCHUMACHER, M. V. Estimativa do carbono da serapilheira em florestas de eucalipto de diferentes idades. In: Congresso Florestal Estadual de Nova Prata, 8, 2000, Nova Prata. Anais. Nova Prata: Prefeitura Municipal, 2000. 